\title{
Comparison of carcass and meat quality traits between lean and fat Pekin ducks
}

\author{
Si-Ran Ding ${ }^{1}$, Guang-Sheng Li ${ }^{1}$, Si-Rui Chen ${ }^{1}$, Feng Zhu ${ }^{1}$, Jin-Ping Hao ${ }^{2}$, \\ Fang-Xi Yang ${ }^{2}$, and Zhuo-Cheng Hou ${ }^{1}{ }^{1 *}$
}

\footnotetext{
* Corresponding Author: Zhuo-Cheng Hou Tel: +86-010-6273-1869

Fax: +86-010-6273-1869,

E-mail: zchou@cau.edu.cn

${ }^{1}$ National Engineering Laboratory for Animal Breeding, Key Laboratory of Animal Genetics, Breeding and Reproduction of the Ministry of Agriculture, College of Animal Science and Technology, China Agricultural University, Beijing 100193, China

2 Beijing Golden Star Duck Center, Beijing 100076, China

ORCID

Si-Ran Ding

https://orcid.org//0000-0002-5566-5996 Guang-Sheng Li

https://orcid.org/0000-0003-4901-3593

Si-Rui Chen

https://orcid.org/0000-0002-7025-1791

Feng Zhu

https://orcid.org/0000-0002-0629-1924 Jin-Ping Hao

https://orcid.org/0000-0003-4418-9602

Fang-Xi Yang

https://orcid.org/0000-0001-6550-1920

Zhuo-Cheng Hou

https://orcid.org/0000-0003-4752-2255
}

Submitted Jul 29, 2019; Revised Sept 15, 2019 ; Accepted Nov 18, 2019
Objective: According to market demand, meat duck breeding mainly includes 2 breeding directions: lean Pekin duck (LPD) and fat Pekin duck (FPD). The aim of the present study was to compare carcass and meat quality traits between 2 strains, and to provide basic data for guidelines of processing and meat quality improvement.

Methods: A total of 62 female Pekin ducks (32 LPDs and 30 FPDs) were slaughtered at the age of 42 days. The live body weight and carcass traits were measured and calculated. Physical properties of breast muscle were determined by texture analyzer and muscle fibers were measured by paraffin sections. The content of inosine monophosphate (IMP), intramuscular fat (IMF) and fatty acids composition were measured by high-performance liquid chromatography, Soxhlet extraction method and automated gas chromatography respectively.

Results: The results showed that the bodyweight of LPDs was higher than that of FPDs. FPDs were significantly higher than LPDs in subcutaneous fat thickness, subcutaneous fat weight, subcutaneous fat percentage, abdominal fat percentage and abdominal fat shear force $(\mathrm{p}<0.01)$. LPDs were significantly higher than FPDs in breast muscle thickness, breast muscle weight, breast muscle rate and breast muscle shear force $(\mathrm{p}<0.01)$. The muscle fiber average area and fiber diameter of LPDs were significantly higher than those of FPDs $(p<0.01)$. The muscle fiber density of LPDs was significantly lower than that of FPDs $(p<0.01)$. The IMF of LPDs in the breast muscle was significantly higher than that in the FPDs $(\mathrm{p}<0.01)$. There was no significant difference between the 2 strains in IMP content ( $p>0.05)$. The polyunsaturated fatty acid content of LPDs was significantly higher than that of FPDs ( $p<0.01)$, and FPDs had higher saturated fatty acid and monounsaturated fatty acid levels $(\mathrm{p}<0.05)$.

Conclusion: Long-term breeding work resulted in vast differences between the two strains Pekin ducks. This study provides a reference for differences between LPD and FPD that manifest as a result of long-term selection.

Keywords: Pekin Duck; Carcass Traits; Meat Quality; Fatty Acids; Intramuscular Fat

\section{INTRODUCTION}

Pekin duck, a world-famous meat duck breed, shows advantageous characteristics such as fast growth, high feed conversion rate, high reproductive rate and strong disease resistance [1]. Pekin ducks account for about $70 \%$ of the annual meat duck production in Asia. In China, there are kinds of dishes that use duck as the raw material, each of which requires different traits of duck. Specifically, roasting requires more fat deposition, braising requires higher meat quality, and soup requires more flavor. To satisfy the different preferences of consumers, the original Pekin duck was selected in 2 different directions: lean Pekin duck (LPD) and fat Pekin duck (FPD) [2,3]. For more than 30 years in China, selection of LPD mainly focused on various carcass traits, including breast muscle yield, feed conversion ratio, 
and growth rate, while in FPD the selection focused on fat traits, including subcutaneous fat ratio and skin thickness. LPD mainly provides meat and its byproducts after slaughter, which has a huge market prospect. FPD is used mainly as raw material for roast duck because of its high subcutaneous fat percentage. In China and Southeast Asia, roast Pekin duck is a classic example of the utilization of the Pekin duck's excellent subcutaneous fat trait utilization [1]. However, the intensive selection on growth rate has resulted in a decline in meat quality and poor flavor characteristics in meat animals [4]. Improving meat quality became a high priority in the breeding of meat duck.

Meat quality is a comprehensive set of characteristics that is composed of multiple traits, including appearance quality traits, eating quality traits and reliance quality traits [5]. Eat quality traits are series of traits affecting the taste and flavor of meat, such as muscle shear force, water loss rate, intramuscular fat (IMF), and inosine monophosphate (IMP). IMF content of the muscle affects the texture and taste of the meat. An increase in IMF content will improve the juiciness, tenderness, water-holding capacity and flavor of the meat $[6,7]$ and is one of the main flavor-determining compounds in poultry muscle. IMP is a substance produced by the decomposition of ATP in the muscles after the death of the animal, which makes the muscle tasty. In addition, sodium glutamate in the muscle can have a make a synergistic effect with IMP, which makes the fresh flavor stronger [8,9]. Duck meat also contains a large number of polyunsaturated fatty acids (PUFAs) [10], while the high essential fatty acids content of duck meat makes it suitable for human health purposes [11]. The muscle fiber is an important component of breast muscle that determines meat quality. The type and diameter of muscle fiber are related to muscle tenderness [12]. In spite of the importance of the issue there are very few studies available on the quality of duck meat.

The objective of this study is to assess the main differences in the carcass and meat quality of 2 different types of Pekin ducks on the market and provide guidelines for breeding, production, and processing of duck meat.

\section{MATERIALS AND METHODS}

\section{Ducks and rearing system}

A total of 62 female Pekin ducks (32 LPDs and 30 FPDs) were reared in Beijing Golden Star Duck Company. Ad libitum feeding and drinking were provided from hatching until the end of the study. The animals were fed a starter diet (from 1 day to 3 weeks of age) containing $19 \%$ crude protein, 12.81 $\mathrm{MJ} / \mathrm{kg}$ dietary metabolizable energy (ME), and a grower diet (from 4 weeks of age till the end of the experiment) containing $17.1 \%$ crude protein and $11.95 \mathrm{MJ} / \mathrm{kg}$ ME. The management and feeding conditions for the LPD and FPD were the same.
The feed content and lighting program was the same as in our previous studies $[13,14]$. All the duck experiments were reviewed and approved by the Animal Care and Use Committee of China Agricultural University with approval number SYXK 2007-0023.

\section{Slaughter and carcass performance}

The experimental ducks were slaughtered at 42 days of age, following fasting for $12 \mathrm{~h}$ prior to slaughter, during which time drinking water was provided freely. Slaughter was carried out according to the standard meat duck slaughtering process. Live body weight, carcass weight, eviscerated weight, breast muscle weight, leg muscle weight, abdominal fat weight and subcutaneous fat weight of the animals were measured. The thickness of subcutaneous fat and breast muscle was measured using an ultrasonic method [14]. The heart, liver, gizzard, abdominal fat, subcutaneous fat and breast muscle were weighed for each duck. The eviscerated weight was obtained by removing the weight of viscera (heart, liver, spleen, gizzard, intestines, crop, esophagus, trachea and reproductive organs), head and feet. The slaughter traits were calculated according to the method described previously $[14,15]$.

\section{Physical properties of breast and subcutaneous fat}

Shear force was used as a representative of meat tenderness. The left breast muscle and subcutaneous fat were used to determine the shear force and free water loss rate. Shear force and free water loss rate were measured by using a texture analyzer (model XTplus Stable Micro Systems, Surrey, UK). The muscle was cut parallel to the longitudinal orientation of muscle fibers and shear force was recorded by means of the texture analyzer (test speed $2 \mathrm{~mm} / \mathrm{s}$; displacement $98 \%$ thickness; trigger force $5 \mathrm{~g}$ ). The water holding capacity (WHC) was measured as weight loss during constant pressure. Using a pair of blades perpendicular to the direction of the muscle fiber to cut the breast muscle with a $1.0 \mathrm{~cm}$ thickness, a sharp circular sampler with a diameter of $2.5 \mathrm{~cm}$ (circular area is 5 $\mathrm{cm}$ ) was used to cut out a sample from the center part and weigh $\mathrm{m} 1$. After weighing, the muscle sample was wrapped in gauze and placed in filter paper, placed on the texture analyzer, pressurized to $35 \mathrm{~kg}$ for $5 \mathrm{~min}$. Immediately after removal of the pressure, it was weighed $\left(\mathrm{m}_{2}\right)$ and the water loss rate was determined as $\mathrm{X}=\left(\mathrm{m}_{1}-\mathrm{m}_{2}\right) / \mathrm{m}_{1} \times 100 \%$.

For measuring muscle fiber diameter, breast meat samples (volume: $2 \mathrm{~cm} \times 1 \mathrm{~cm} \times 1 \mathrm{~cm}$ ) were cut along the same part of muscle fibers and stored in formalin solution for $48 \mathrm{~h}$. After being washed with tap water, they were dehydrated in an ethanol series. The meat samples were immersed in xylene: ethanol (1:1) solution and then embedded in paraffin. Paraffin sections $(10 \mu \mathrm{m})$ were cut and stained with hematoxylin and eosin. The sections were photographed with a microscope at 400× magnification (Figure 1) and histologically 


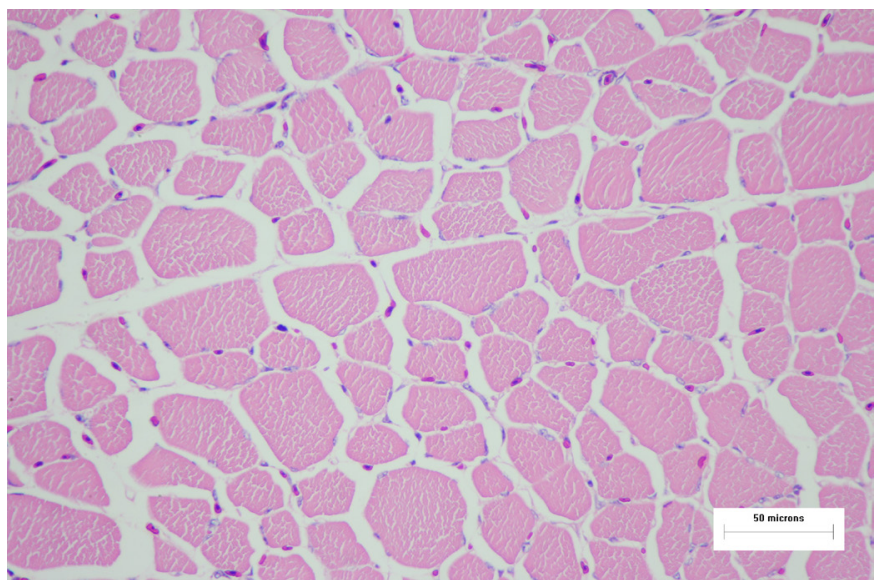

LPD

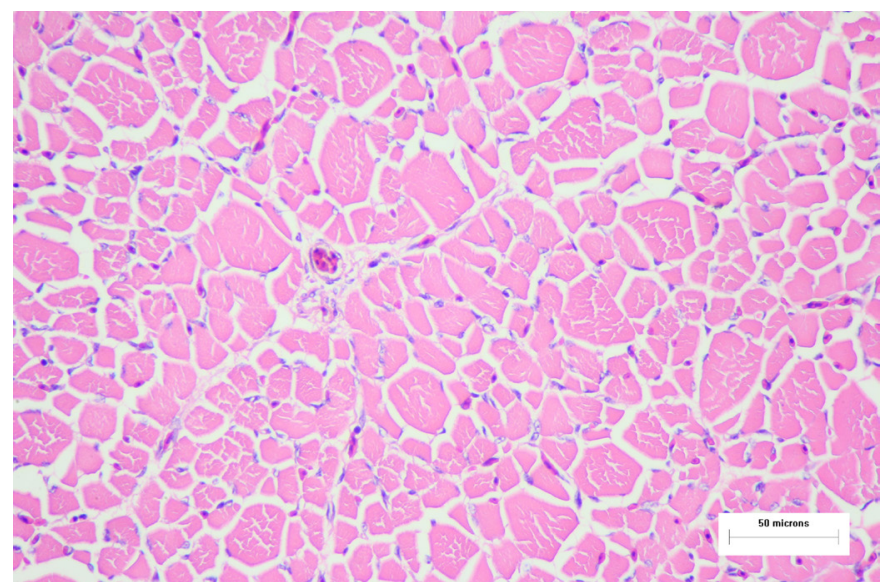

FPD

Figure 1. Paraffin section of breast muscle of lean Pekin duck (LPD) and fat Pekin duck (FPD) (400x magnification). This is a cross-sectional view of the pectoral muscle of 2 strains of Pekin duck. The red parts of the picture are a cross section of the breast muscle fibers.

analyzed with Image-Pro Plus version 6.0 software to determine the average area of muscle fibers, average diameter, average density and the ratio of length diameter to width diameter.

\section{Inosine monophosphate in the breast muscle}

Samples were trimmed of all visible connective tissue and fat. The right breast muscle was made into a meat paste and stored at $-20^{\circ} \mathrm{C}$. Meat samples (approximately $5 \mathrm{~g}$ ) were homogenized with $20 \mathrm{~mL} \mathrm{5 \%}$ perchloric acid and centrifuged at $4,000 \mathrm{rpm}$ at $10^{\circ} \mathrm{C}$. The supernatant was diluted with $15 \mathrm{~mL}$ $5 \%$ perchloric acid and filtered. The $\mathrm{pH}$ of the filtrate was adjusted to 6.5 with sodium hydroxide solution, adjusted to $100 \mathrm{~mL}$, filtered using a $0.22 \mu \mathrm{m}$ membrane and the IMP content was determined by high-performance liquid chromatography.

\section{Intramuscular fat in the breast muscle}

Hydrochloric acid solution ( $2 \mathrm{~mol} / \mathrm{L}$ ) was added to $3 \mathrm{~g}$ of breast muscle paste prepared previously and the mix was gently boiled for $1 \mathrm{~h}$. It was then washed after drying at $103^{\circ} \mathrm{C}$ for $1 \mathrm{~h}$, using the Soxhlet extraction method [16]. The IMF content was calculated by dividing the weight of fat by the total weight of the sample.

\section{Fatty acids in the breast muscle}

Before the determination of fatty acid composition, duck breast muscle stored at $-20^{\circ} \mathrm{C}$ was taken out of the freezer before measuring fatty acids and then frozen under vacuum at $-20^{\circ} \mathrm{C}$ for $72 \mathrm{~h}$. For the determination of fatty acid composition, the sample was added into a $4 \mathrm{~mL}$ reaction bottle. The fatty acid was methylated by $6 \mathrm{~mL}$ of $10 \%$ acetyl chloride methanol (acetyl chloride has a volume of $10 \%$ of methanol) solution, then the sample was filled with nitrogen, and a water bath was conducted at $80^{\circ} \mathrm{C}$ for $2 \mathrm{~h}$. After $1 \mathrm{~mL}$ normal hexane was added into the reaction system and shaken, $1.5 \mathrm{~mL}$ of $6 \%$ potassium carbonate solution was added. After shaking, the supernatant was taken into the sample bottle and sent to the automatic gas chromatography for determination. The analysis was performed on an Agilent 7890 gas chromatograph with a flame ionization detector, using a DB-23 column $(60 \mathrm{~m} \times 250 \mu \mathrm{m} \times 0.2 \mu \mathrm{m})$ for detecting fatty acid methyl esters (FAME). The initial temperature of the oven was set at $50^{\circ} \mathrm{C}$ for $2 \mathrm{~min}$, rising to $175^{\circ} \mathrm{C}$ for $3 \mathrm{~min}$ at a speed of $25^{\circ} \mathrm{C}$ per minute. Then the column temperature was raised at $5^{\circ} \mathrm{C} / \mathrm{min}$ to $200^{\circ} \mathrm{C}$, and immediately to $210^{\circ} \mathrm{C}$ at a rate of $1.5^{\circ} \mathrm{C} / \mathrm{min}$. Finally, it rises to $230^{\circ} \mathrm{C}$ at $2^{\circ} \mathrm{C} / \mathrm{min}$ where it remained for $6 \mathrm{~min}$. The detector and injector were both at $250^{\circ} \mathrm{C}$ and the flow rate was set at $1.2 \mathrm{~mL} / \mathrm{min}$. The peak of FAMEs was identified by comparison with the similar retention time and quantified for the 37 component FAMEs mix (Supelco, 37 Component FAME mix C4-C24) as an external marker (analyzed by the GC Chem Station software of Agilent, Palo Alto, CA, USA).

\section{Statistical analysis}

Statistical analyses were performed using the $\mathrm{R}$ statistical software (version 3.4.3). Differences between the 2 strains of Pekin ducks were tested by Student's $t$-test. Spearman's simple correlation between the different traits was calculated. The principal component analysis (PCA) was used to analyze the dimension cluster of the measured 12 carcass and meat quality traits. The purpose of using PCA was to condense the original information into a smaller number of representative traits to discriminate the 2 lines and also explore relationships among traits. Differences were considered significant at the $\mathrm{p}<0.05$ or $\mathrm{p}<0.01$ level. 


\section{RESULTS}

\section{Comparison of slaughter performance between LPD and FPD}

The live body, carcass, and eviscerated weight of the LPD were significantly higher than those of the FPD $(\mathrm{p}<0.01)$ at the age of 42 days (Table 1). LPD had a significantly higher eviscerated rate than FPD $(\mathrm{p}<0.05)$. The carcass rate was similar between the 2 lines ( $\mathrm{p}>0.05)$.

\section{Comparison of fat properties between LPD and FPD}

Fat-related traits of the 2 strains are shown in Table 2. The results indicate that the thickness of the subcutaneous fat, subcutaneous fat weight, subcutaneous fat percentage, abdominal fat percentage and subcutaneous fat shear force of the FPD were significantly higher than those of the LPD (1.76 $\mathrm{mm}, 668.73 \mathrm{~g}, 35.81 \%, 2.62 \%$ and $12.18 \mathrm{~N}$ vs $1.23 \mathrm{~mm}, 562.34$ g, $23.64 \%, 1.21 \%$ and $7.91 \mathrm{~N}$, respectively, $\mathrm{p}<0.01$ ). There was no significant difference in the density of pores between the 2 strains $(\mathrm{p}>0.05)$.

\section{Comparison of physical properties between LPD and FPD breast muscle}

The physical properties of the breast muscles are shown in Table 3. The thickness of breast muscle, breast muscle weight, breast muscle rate and the shear force of breast muscle were significantly higher in 42-day-old LPDs than FPDs (19.67 $\mathrm{mm}, 455.72 \mathrm{~g}, 19.14 \%, 15.78 \mathrm{~N}$ vs $10.43 \mathrm{~mm}, 182.73 \mathrm{~g}, 9.81 \%$,

Table 1. Comparison of slaughter performance between LPD and FPD

\begin{tabular}{lcc}
\hline Traits & LPD & FPD \\
\hline Live body weight $(\mathrm{g})$ & $3,402.19 \pm 206.51^{\mathrm{A}}$ & $2,781.47 \pm 136.75^{\mathrm{B}}$ \\
Carcass weight $(\mathrm{g})$ & $3,000.27 \pm 185.07^{\mathrm{A}}$ & $2,461.23 \pm 123.94^{\mathrm{B}}$ \\
Eviscerated weight $(\mathrm{g})$ & $2,378.25 \pm 146.77^{\mathrm{A}}$ & $1,863.63 \pm 103.61^{\mathrm{B}}$ \\
Carcass rate (\%) & $82.89 \pm 21.76$ & $88.73 \pm 6.76$ \\
Eviscerated rate (\%) & $69.93 \pm 2.03^{\mathrm{a}}$ & $67.20 \pm 5.45^{\mathrm{b}}$ \\
\hline
\end{tabular}

LPD, lean Pekin duck; FPD, fat Pekin duck.

$A, B$ Different upper case letters as superscripts in the same row indicate very significant differences $(p<0.01)$.

$a, b$ Different lower case letters denote significant differences $(p<0.05)$.

Table 2. Comparison of fat properties between LPD and FPD

\begin{tabular}{lcc}
\hline Traits & LPD & FPD \\
\hline Thickness of subcutaneous fat & $1.23 \pm 0.37^{\mathrm{B}}$ & $1.76 \pm 0.31^{\mathrm{A}}$ \\
$(\mathrm{mm})$ & $562.34 \pm 61.12^{\mathrm{B}}$ & $668.73 \pm 72.02^{\mathrm{A}}$ \\
Subcutaneous fat weight (g) & $23.64 \pm 2.06^{\mathrm{B}}$ & $35.81 \pm 2.22^{\mathrm{A}}$ \\
Subcutaneous fat percentage (\%) & $1.21 \pm 0.50^{\mathrm{B}}$ & $2.62 \pm 0.43^{\mathrm{A}}$ \\
Abdominal fat percentage (\%) & $7.91 \pm 2.55^{\mathrm{B}}$ & $12.18 \pm 2.42^{\mathrm{A}}$ \\
Subcutaneous fat shear force (N) & $9.72 \pm 1.19$ & $10.03 \pm 0.92$ \\
\hline Density of pores (N/cm $\left.{ }^{2}\right)$ &
\end{tabular}

LPD, lean Pekin duck; FPD, fat Pekin duck.

$A, B$ Different superscripts in the same row indicate significant differences $(p<0.01)$.
Table 3. Comparison of physical properties between LPD and FPD breast muscle

\begin{tabular}{lcc}
\hline Traits & LPD & FPD \\
\hline Breast muscle thickness $(\mathrm{mm})$ & $19.67 \pm 2.03^{\mathrm{A}}$ & $10.43 \pm 1.03^{\mathrm{B}}$ \\
Breast muscle weight $(\mathrm{g})$ & $455.72 \pm 49.47^{\mathrm{A}}$ & $182.73 \pm 18.26^{\mathrm{B}}$ \\
Breast muscle rate $(\%)$ & $19.14 \pm 1.38^{\mathrm{A}}$ & $9.81 \pm 0.88^{\mathrm{B}}$ \\
Breast muscle water loss $(\%)$ & $39.52 \pm 2.05$ & $40.54 \pm 2.01$ \\
Breast muscle shear force $(\mathrm{N})$ & $15.78 \pm 4.12^{\mathrm{A}}$ & $10.75 \pm 1.48^{\mathrm{B}}$ \\
Area of muscle fiber $\left(\mu \mathrm{m}^{2}\right)$ & $378.42 \pm 98.37^{\mathrm{A}}$ & $149.34 \pm 28.57^{\mathrm{B}}$ \\
Diameter of muscle fiber $(\mu \mathrm{m})$ & $28.02 \pm 3.71^{\mathrm{A}}$ & $17.76 \pm 1.68^{\mathrm{B}}$ \\
ratio of the longer to & $1.78 \pm 0.07$ & $1.81 \pm 0.06$ \\
$\quad$ the shorter diameter & & \\
Density of muscle fiber & $1,368.74 \pm 349.16^{\mathrm{B}}$ & $2,856.58 \pm 429.88^{\mathrm{A}}$ \\
$\quad\left(\mathrm{N} / \mathrm{mm}^{2}\right)$ & & \\
\hline LPD, lean Pekin duck; FPD, fat Pekin duck. & \\
A,B Different superscripts in the same row indicate significant differences \\
( $\mathrm{p}<0.01)$.
\end{tabular}

$10.75 \mathrm{~N}$, respectively, $\mathrm{p}<0.01)$. There was no significant difference in the water loss rate between the 2 groups ( $>0.05$ ). The average area of muscle fiber and the diameter of muscle fiber in the LPD group were significantly higher than those in the FPDs (378.42 vs $149.34 \mu \mathrm{m}^{2}$ and 28.02 vs $17.76 \mu \mathrm{m}$, respectively, $\mathrm{p}<0.01)$. The density of muscle fiber was significantly in the LPD than in the FPD group ( $\mathrm{p}<0.01$ ), but there was no significant difference in the ratio of the longer diameter to the shorter diameter of muscle fiber $(p>0.05)$. Finally, based on the paraffin sections, the muscle fibers of FPDs were clearly denser, and the diameter and area of muscle fibers were also significantly smaller than those of LPDs.

\section{Comparison of the content of IMP, IMF and fatty acids} in breast muscle between LPD and FPD

The contents of IMP and IMF are shown in Table 4, and the composition of fatty acids are presented in Table 5. No obvious difference in the IMP content of breast muscle was found between LPDs and FPDs ( 0.85 vs $0.79 \mathrm{mg} / \mathrm{g}, \mathrm{p}>0.05$ ), while a significant difference was found in the IMF content of breast muscle between the 2 groups ( $1.44 \%$ vs $1.22 \%, \mathrm{p}<0.01$ ). The composition of fatty acids in the breast muscle in the 2 strains were similar, with the top five fatty acids being arachidonic acid (C20:4, 23\% to $24 \%$ ), oleic acid (C18:1, 19\% to $20 \%)$, linoleic acid (C18:2, 14\% to 16\%), palmitic acid (C16:0, 12\%) and stearic acid (C18:0,11\%), accounting for more than $80 \%$

Table 4. Comparison of inosine monophosphate and intramuscular fat content of breast muscle between LPD and FPD

\begin{tabular}{lcl}
\hline Traits & LPD & \multicolumn{1}{c}{ FPD } \\
\hline IMP $(\mathrm{mg} / \mathrm{g})$ & $0.85 \pm 0.15$ & $0.79 \pm 0.10$ \\
$\mathrm{IMF}(\%)$ & $1.44 \pm 0.40^{\mathrm{A}}$ & $1.22 \pm 0.20^{\mathrm{B}}$ \\
\hline
\end{tabular}

LPD, lean Pekin duck; FPD, fat Pekin duck; IMP, inosine monophosphate; IMF, intramuscular fat.

$\mathrm{A}, \mathrm{B}$ Different superscripts in the same row indicate significant differences $(p<0.01)$ 
Table 5. Comparison of fatty acids in breast muscle

\begin{tabular}{|c|c|c|c|c|c|}
\hline \multirow{2}{*}{ Fatty acids } & \multicolumn{2}{|c|}{ Strain } & \multirow{2}{*}{ Fatty acid } & \multicolumn{2}{|c|}{ Strain } \\
\hline & LPD & FPD & & LPD & FPD \\
\hline $\mathrm{C} 4: 0$ & $0.01 \pm 0.003$ & $0.01 \pm 0.002$ & C16:1 & $0.18 \pm 0.08$ & $0.18 \pm 0.07$ \\
\hline $\mathrm{C} 6: 0$ & $0.01 \pm 0.004$ & $0.01 \pm 0.004$ & $\mathrm{C} 17: 1$ & $0.16 \pm 0.03^{B}$ & $0.19 \pm 0.02^{A}$ \\
\hline C11:0 & $0.02 \pm 0.004$ & $0.02 \pm 0.004$ & C18:1 & $5.70 \pm 2.05$ & $5.82 \pm 1.70$ \\
\hline C14:0 & $0.06 \pm 0.03$ & $0.05 \pm 0.02$ & $\mathrm{C} 20: 1$ & $0.14 \pm 0.03^{A}$ & $0.13 \pm 0.020^{\mathrm{B}}$ \\
\hline C15:0 & $0.01 \pm 0.01^{a}$ & $0.01 \pm 0.003^{b}$ & C24:1 & $0.13 \pm 0.02^{B}$ & $0.23 \pm 0.05^{A}$ \\
\hline C16:0 & $3.47 \pm 0.75$ & $3.46 \pm 0.51$ & MUFA & $7.16 \pm 2.14$ & $7.56 \pm 1.80$ \\
\hline C17:0 & $0.14 \pm 0.03^{A}$ & $0.11 \pm 0.01^{\mathrm{B}}$ & C18:2 & $4.78 \pm 1.13^{A}$ & $4.11 \pm 0.60^{B}$ \\
\hline C18:0 & $3.36 \pm 0.36$ & $3.27 \pm 0.19$ & C18:3 & $0.08 \pm 0.04^{a}$ & $0.06 \pm 0.02^{b}$ \\
\hline C20:0 & $0.09 \pm 0.01^{\mathrm{B}}$ & $0.10 \pm 0.01^{\mathrm{A}}$ & C20:2 & $0.81 \pm 0.12$ & $0.85 \pm 0.11$ \\
\hline C21:0 & $0.49 \pm 0.14$ & $0.55 \pm 0.12$ & C20:3 & $0.81 \pm 0.11^{b}$ & $0.87 \pm 0.10^{a}$ \\
\hline C22:0 & $0.04 \pm 0.01^{A}$ & $0.03 \pm 0.01^{\mathrm{B}}$ & C20:4 & $6.89 \pm 0.61^{A}$ & $6.31 \pm 0.52^{B}$ \\
\hline C23:0 & $0.02 \pm 0.01$ & $0.02 \pm 0.01$ & C20:5 & $0.07 \pm 0.01^{B}$ & $0.08 \pm 0.01^{A}$ \\
\hline C24:0 & $0.17 \pm 0.01^{A}$ & $0.16 \pm 0.01^{\mathrm{B}}$ & $\mathrm{C} 22: 2$ & $0.02 \pm 0.01^{B}$ & $0.03 \pm 0.01^{A}$ \\
\hline SFA & $7.89 \pm 1.20$ & $7.79 \pm 0.75$ & $\mathrm{C} 22: 6$ & $0.05 \pm 0.01^{B}$ & $0.06 \pm 0.01^{A}$ \\
\hline C15:1 & $0.86 \pm 0.08^{B}$ & $1.01 \pm 0.07^{\mathrm{A}}$ & PUFA & $13.50 \pm 1.46^{\mathrm{A}}$ & $12.36 \pm 0.79^{B}$ \\
\hline
\end{tabular}

The values are dry matter content.

LPD, lean Pekin duck; FPD, fat Pekin duck; MUFA, monounsaturated fatty acid; SFA, saturated fatty acid; PUFA, polyunsaturated fatty acids

$A, B$ Different upper case letters as superscripts in the same row indicate strong significant differences $(p<0.01)$.

$a, b$ Different lower case letters denote significant differences $(p<0.05)$.

of the total fatty acids. The PUFA content of the LPD was significantly higher than that of the FPD $(\mathrm{p}<0.01)$.

\section{Correlation analysis between different traits}

The result of correlation analysis is shown in Table 6. IMF content of the breast muscle is positively correlated with live body weight and the breast muscle rate $(r=0.39$ and $r=0.32$, respectively, $\mathrm{p}<0.01$ ), and is negatively correlated with the subcutaneous fat percentage and the abdominal fat percentage $(\mathrm{r}=-0.36$ and $\mathrm{r}=-0.33$, respectively, $\mathrm{p}<0.01)$. The diameter of muscle fiber showed a positive correlation with the IMP content $(\mathrm{r}=0.27, \mathrm{p}<0.05)$. In addition, it is also negatively correlated with the IMF content $(r=-0.32, \mathrm{p}<0.01)$.

\section{Principal component analysis}

The first three principal components (PC1, PC2, and PC3) with eigenvalues higher than 1 which were extracted from the 12 original traits, can explain the $81.27 \%$ cumulative variance. While the PC1 predominates account for $60.17 \%$ of the cumulative variance. There were three groups of variables in the projection of first two principal components (Figure 2). The first group includes the fat-related traits (thickness of subcutaneous fat, abdominal fat weight, subcutaneous fat weight); the second group includes the gizzard while the third group includes the remaining 8 traits (live body weight, carcass weight, thickness of breast muscle, breast muscle weight, heart weight, liver weight, head weight). The results indicate

Table 6. Correlation of some traits in Pekin ducks

\begin{tabular}{|c|c|c|c|c|c|}
\hline Items & IMF & $\begin{array}{c}\text { Area of } \\
\text { muscle fiber }\end{array}$ & $\begin{array}{l}\text { Diameter of } \\
\text { muscle fiber }\end{array}$ & $\begin{array}{l}\text { Ratio of the longer to } \\
\text { the shorter diameter }\end{array}$ & $\begin{array}{c}\text { Density of } \\
\text { muscle fiber }\end{array}$ \\
\hline Live body weight & $0.39 \star \star$ & $0.79 \star \star$ & $0.81 * \star$ & -0.15 & $-0.85^{\star \star}$ \\
\hline Carcass rate & -0.16 & -0.11 & -0.13 & -0.23 & 0.18 \\
\hline Eviscerated rate & -0.1 & $0.26 *$ & $0.25^{\star}$ & $-0.28 *$ & -0.19 \\
\hline Subcutaneous fat percentage & $-0.36 \star \star$ & $-0.8 \star \star$ & $-0.84^{\star \star}$ & 0.11 & $0.86^{\star \star}$ \\
\hline Breast muscle rate & $0.32 \star \star$ & $0.87 \star \star$ & $0.9 \star \star$ & -0.11 & $-0.91 \star \star$ \\
\hline Abdominal fat percentage & $-0.33^{\star \star}$ & $-0.77 \star \star$ & $-0.8^{\star \star}$ & 0.07 & $0.8^{\star \star}$ \\
\hline Breast water loss & -0.04 & -0.21 & -0.22 & -0.04 & 0.17 \\
\hline Breast shear force & 0.12 & $0.6^{\star \star}$ & $0.59 \star \star$ & $-0.26^{\star}$ & $-0.58 \star \star$ \\
\hline IMP & 0.24 & 0.24 & $0.27 \star$ & 0.04 & $-0.25^{\star}$ \\
\hline IMF & 1 & $0.27 \star$ & $0.32 \star \star$ & 0 & $-0.33^{\star \star}$ \\
\hline
\end{tabular}

IMP, inosine monophosphate; IMF, intramuscular fat.

** Denotes significant level at $p<0.01$, and * indicates significant level at $p<0.05$. 


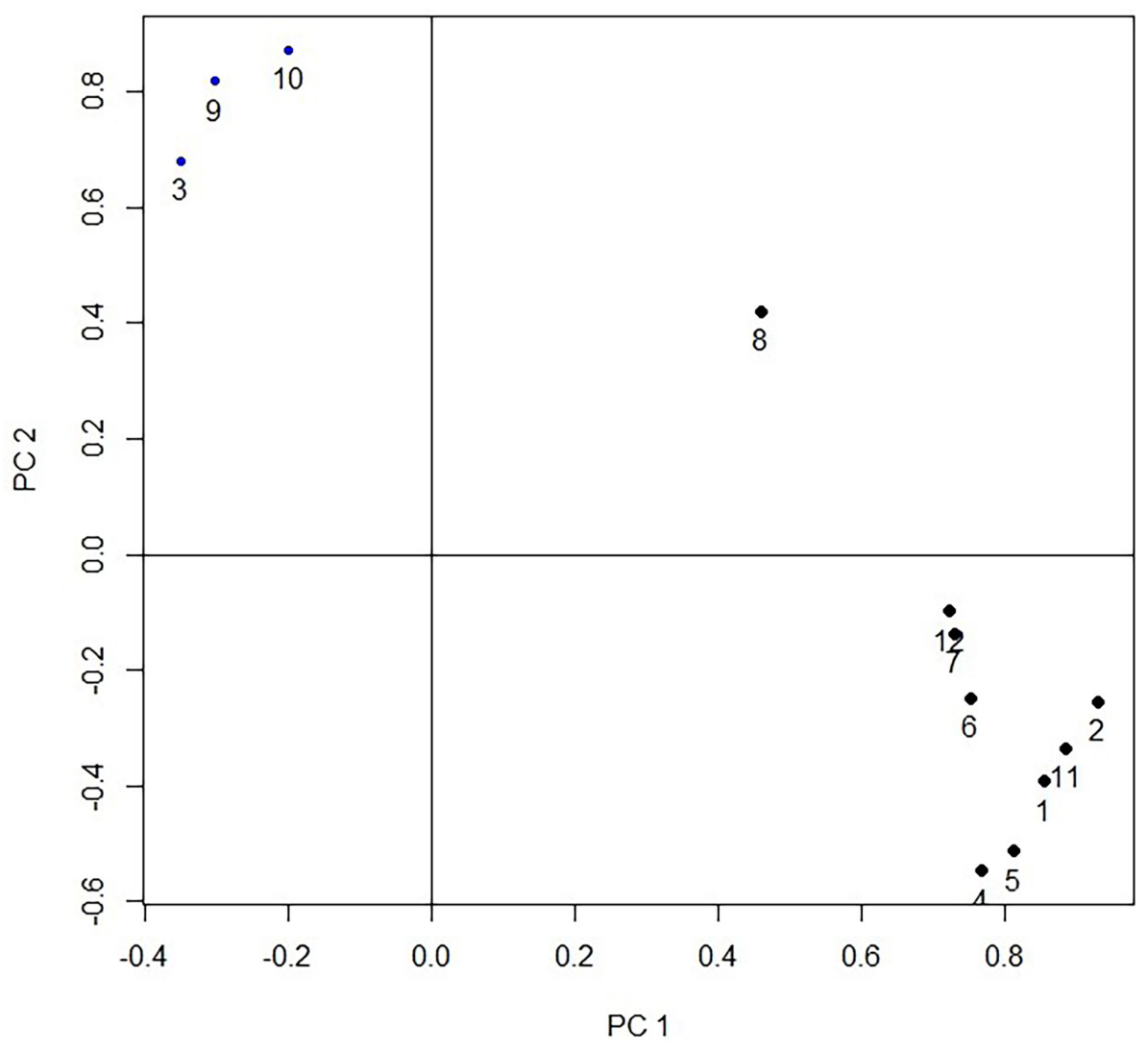

Figure 2. Projection of the carcass traits measurements by the 2 first principal components. $1=$ live body weight; $2=$ carcass weight; $3=$ thickness of subcutaneous fat; 4 = thickness of breast muscle; 5 = breast muscle weight; 6 = heart weight; $7=$ liver weight; $8=$ gizzard weight; $9=$ abdominal fat weight; 10 = subcutaneous fat weight; 11 = eviscerated weight; 12 = head weight.

that the current 12 carcass traits could be divided into three categories. In PC1, the vector projection of the thickness of subcutaneous fat, abdominal fat weight, and subcutaneous fat weight, indicates that fat traits are the most important traits that can discriminate the different strains (Figure 2).
The projection of the individual of 2 strains in the plane defined by the three principal components is shown in Figure 3, which indicates that FPDs and LPDs are clustered together, and the distribution area of the 2 strains has a clear line of demarcation.

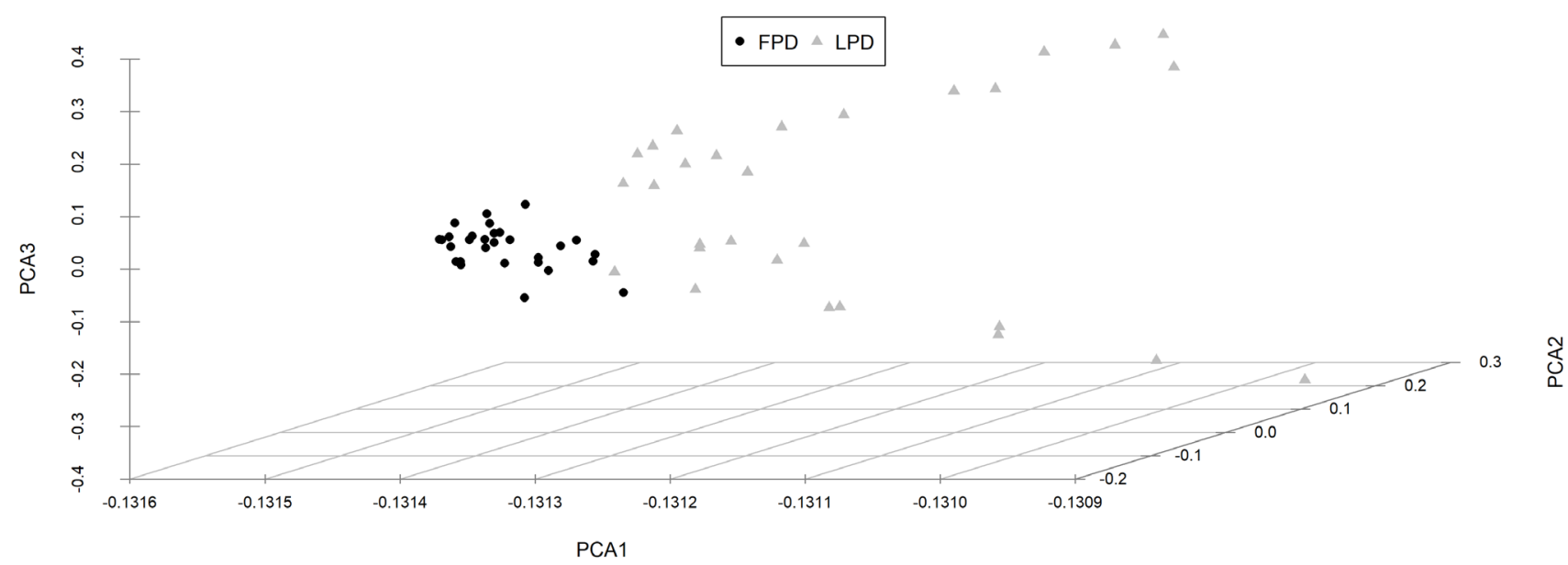

Figure 3. Projection of 1 individual of each strain in the plane defined by the three principal components. Comp.1, Comp.2, Comp.3 represent the first, second and third principal component, respectively. Each point in the figure represents 1 individual. 


\section{DISCUSSION}

The yield and meat quality are important factors influencing the sale price and consumer preference. Compared with broilers, Pekin duck has a significantly higher eviscerated rate and has more meat value $[17,18]$. In the present study, the slaughter rate of Pekin ducks was higher than $80 \%$, and the eviscerated rate was higher than $65 \%$. This showed that both LPD and FPD had excellent meat production performance. The high subcutaneous fat weight, subcutaneous fat percentage, and subcutaneous fat thickness are the most important traits for the FPD line, which is normally preferred as raw material for roast Pekin duck. There was a significant difference between the 2 strains in the shear force of subcutaneous fat, which is due to selective breeding for the subcutaneous fat thickness of the FPD. Additional work is needed to improve the IMF content of duck breast muscle. After a long period of divergent selection, FPD and LPD lines show significant differences in carcass traits, especially fat-related traits. Interestingly, the gizzard weight was used as the third independent trait while we found no difference between the 2 strains. This suggests that artificial selection on growth and fat deposition does not have a significant large effect on gizzard weight.

IMP, as a substance that contributes to the determination of meat flavor, plays an important role in giving the umami taste of muscle and is also one of the important flavor indexes [8]. IMP has a great influence on the taste of breast meat. Different studies found great variations in IMP content, both within and among species. IMP content from various studies in chickens ranged from 1.40 to $1.81 \mathrm{mg} / \mathrm{g}[19,20]$. A few studies available in ducks also showed large variations in IMP content. Cherry Valley ducks had about $1.55 \mathrm{mg} / \mathrm{g}$ IMP in the breast muscle [21]. However, since IMP content is greatly influenced by nutrition, breeds, and storage time, more work should be performed from both of those selection aspects. The limited number of studies about the heritability of IMP in chicken and other species showed that IMP has low heritability [22]. In the experimental population, the IMP content showed a large coefficient of variance $(12.7 \%$ and $17.6 \%)$, indicating that IMP had a possibility for improvement. Studies have shown that tenderness and flavor of duck breast are related to the IMF content [23]. However, we found no significant correlation between tenderness and IMF content in this study. IMF content in the breast muscle did not correlate with subcutaneous fat weight either. In addition, we found a significant negative correlation between IMF and other fat traits (subcutaneous fat and abdominal fat), which may indicate that the deposition of IMF is different from that of subcutaneous fat. These results may have an important impact on duck breeding when considering IMF in the breast muscle and body fat content.
The composition of fatty acids is also an important factor affecting the meat flavor. Excessive intake of saturated fatty acid (SFA) is believed to lead to a series of diseases in humans, and the higher the unsaturated fatty acid content in the meat, especially PUFAs, the more beneficial effect on human health can be expected. A previous study suggested that the PUFA: SFA (P:S) ratio in food intake was determined to be above 0.4 [24]. The P:S ratio in Pekin duck was close to 2 in this study, which is considered suitable for human health purposes. However, the n-3 PUFA content in our study was less than that reported by others $[25,26]$. Although there are some differences between the 2 strains, the composition of total fatty acids was similar in general between two strains. Compared to the content and composition of red meat (pork, beef, and mutton) found in other studies, Pekin duck showed clear differences compared to those meat types in terms of fatty acids composition. In general, red meat has a high proportion of SFA, resulting in a low ratio of P:S (0.3 to 0.4); C18:1 and C16:0 are dominant in red meat [24]. By contrast, the fatty acids in Pekin duck breast muscle are mainly unsaturated fatty acids and C20:4 is the major component of total fatty acids [27-31] .

LPD has much higher breast muscle yield than FPD. The selection has also led to large differences in various muscle quality-related traits between the two lines. Tenderness is thought to be an important index for discriminating the meat quality. It was reported that the diameter of muscle fibers affects the tenderness of the muscle [5]. A previous study showed that there was a significant positive correlation between the diameter of breast muscle fibers and the shear force in broilers [32]. The results of the present study support those findings. FPD has more tender breast muscles, which is regarded as more suitable for the traditional roast duck. It was shown previously that increasing the area of muscle fibers make the meat darker and causes a higher WHC in broilers [33], while muscle growth mainly increases the size of muscle cells [3]. In the present research, the interval between the breast muscle fibers as well as the size of the muscle fibers was larger in LPD compared to those in FPD, and it is speculated that there may be more connective tissue and adipocytes between the muscle fibers in the LPD strain. The IMF in the LPD breast muscle was also higher than in the FPD, which also supports the hypothesis that there may be more adipocytes between the muscle fibers in the LPD. However, more work is needed to test this hypothesis.

In conclusion, the long-term selection of fat-related traits and body growth-related traits resulted in distinct differences in meat characteristics between the 2 duck lines. There were significant differences in growth rate, subcutaneous fat percentage, shear force, and other indicators. The P:S ratio in both types of duck meat is high, which makes it an ideal meat-type from a dietary standpoint. This study provided general car- 
cass and meat quality parameters for the 2 most popular Pekin duck strains.

\section{CONFLICT OF INTEREST}

We certify that there is no conflict of interest with any financial organization regarding the material discussed in the manuscript. Hao JP, Yang FX are employees of Beijing Golden Star Duck Center.

\section{ACKNOWLEDGMENTS}

The work was supported by the National Waterfowl-industry Technology Research System (CARS-42-9), National Scientific Supporting Projects of China (2015BAD03B06), Program for Changjiang Scholars and Innovative Research Team in University (IRT_15R62) and Primary Research \& Development Plan of Jiangsu Province (BE2017349). We are grateful to Zoltan Machaty for careful review of the manuscript.

\section{REFERENCES}

1. Zheng AJ, Chang WH, Hou SS et al. Unraveling molecular mechanistic differences in liver metabolism between lean and fat lines of Pekin duck (Anas platyrhynchos domestica): A proteomic study. J Proteomics 2014;98:271-88. https://doi. org/10.1016/j.jprot.2013.12.021

2. Zhang Z, Jia Y, Chen Y, et al. Genomic variation in Pekin duck populations developed in three different countries as revealed by whole-genome data. Anim Genet 2018;49:132-6. https://doi.org/10.1111/age.12639

3. Xu T, Gu L, Schachtschneider KM, et al. Identification of differentially expressed genes in breast muscle and skin fat of postnatal Pekin duck. Plos One 2014;9:e107574. https:// doi.org/10.1371/journal.pone.0107574

4. Yang S, Wang Y, Wang L, et al. RNA-Seq reveals differentially expressed genes affecting polyunsaturated fatty acids percentage in the Huangshan Black chicken population. Plos One 2018;13:e195132. https://doi.org/10.1371/journal.pone.0195 132

5. Joo ST, Kim GD, Hwang YH, Ryu YC. Control of fresh meat quality through manipulation of muscle fiber characteristics. Meat Sci 2013;95:828-36. https://doi.org/10.1016/j.meatsci. 2013.04.044

6. Chartrin P, Meteau K, Juin H, et al. Effects of intramuscular fat levels on sensory characteristics of duck breast meat. Poult Sci 2006;85:914-22. https://doi.org/10.1093/ps/85.5.914

7. Cui HX, Liu RR, Zhao GP, et al. Identification of differentially expressed genes and pathways for intramuscular fat deposition in pectoralis major tissues of fast-and slow-growing chickens. BMC Genomics 2012;13:213. https://doi.org/10.1186/14712164-13-213
8. Ye MH, Chen JL, Zhao GP, Zheng MQ, Wen J. Correlation between polymorphisms in ADSL and GARS-AIRS-GART genes with inosine 5 -monophosphate (IMP) contents in Beijing-you chickens. Br Poult Sci 2010;51:609-13. https:// doi.org/10.1080/00071668.2010.508486

9. Aliani M, Farmer LJ, Kennedy JT, Moss BW, Gordon A. Postslaughter changes in ATP metabolites, reducing and phosphorylated sugars in chicken meat. Meat Sci 2013;94:55-62. https://doi.org/10.1016/j.meatsci.2012.11.032

10. Qiao Y, Huang J, Chen Y, et al. Meat quality, fatty acid composition and sensory evaluation of cherry valley, spent layer and crossbred ducks. Anim Sci J 2017;88:156-65. https://doi. org/10.1111/asj.12588

11. Heo KN, Hong EC, Kim CD, et al. Growth performance, carcass yield, and quality and chemical traits of meat from commercial Korean native ducks with 2-way crossbreeding. Asian-Australas J Anim Sci 2015;28:382-90. https://doi.org/ 10.5713/ajas.13.0620

12.Smith DP, Fletcher DL. Chicken breast muscle fiber type and diameter as influenced by age and intramuscular location. Poult Sci 1988;67:908-13. https://doi.org/10.3382/ps.0670 908

13.Zhu F, Gao YH, Lin FB, Hao JP, Yang FX, Hou ZC. Systematic analysis of feeding behaviors and their effects on feed efficiency in Pekin ducks. J Anim Sci Biotechnol 2017;8:81. https://doi. org/10.1186/s40104-017-0212-2

14.Lin FB, F Zhu, Hao JP, Yang FX, Hou ZC. In vivo prediction of the carcass fatness using live body measurements in Pekin ducks. Poult Sci 2018;97:2365-71. https://doi.org/10.3382/ ps/pey079

15. Narinc D, Karaman E, Aksoy T. Effects of slaughter age and mass selection on slaughter and carcass characteristics in 2 lines of Japanese quail. Poult Sci 2014;93:762-9. https://doi. org/10.3382/ps.2013-03506

16.Zerehdaran S, Vereijken AL, van Arendonk JA, van der Waaijt EH. Estimation of genetic parameters for fat deposition and carcass traits in broilers. Poult Sci 2004;83:521-5. https://doi. org/10.1093/ps/83.4.521

17.Keralapurath MM, Corzo A, Pulikanti R, Zhai W, Peebles ED. Effects of in ovo injection of L-carnitine on hatchability and subsequent broiler performance and slaughter yield. Poult Sci 2010;89:1497-501. https://doi.org/10.3382/ps.2009-00551

18. Adamski MP, Kowalczyk AM, Lukaszewicz ET, Korzeniowska M. Effects of sex and inclusion of dried distillers grains with solubles on slaughter yield and meat characteristics of Pekin ducks. Br Poult Sci 2011;52:742-9. https://doi.org/10.1080/ 00071668.2011.639745

19.Hu J, Yu P, Ding XL, Xu ML, Guo BP, Xu YY. Genetic polymorphisms of the AMPD1 gene and their correlations with IMP contents in Fast Partridge and Lingshan chickens. Gene 2015;574:204-9. https://doi.org/10.1016/j.gene.2015.08.008 20.Yin HD, Gilbert ER, Chen SY, et al. Effect of hybridization 
on carcass traits and meat quality of erlang mountainous chickens. Asian-Australas J Anim Sci 2013;26:1504-10. https:// doi.org/10.5713/ajas.2013.13097

21. Wang DY, Deng SY, Zhang MH, et al. The effect of adenosine 5'-monophosphate (AMP) on tenderness, microstructure and chemical-physical index of duck breast meat. J Sci Food Agric 2016;96:1467-73. https://doi.org/10.1002/jsfa.7243

22.Chen JL, Zhao GP, Zheng MQ, Wen J, Yang N. Estimation of genetic parameters for contents of intramuscular fat and inosine-5'-monophosphate and carcass traits in Chinese Beijing-You chickens. Poult Sci 2008;87:1098-104. https:// doi.org/10.3382/ps.2007-00504

23. He J, Chen J, Lu L, et al. A novel SNP of liver-type fatty acidbinding protein gene in duck and its associations with the intramuscular fat. Mol Biol Rep 2012;39:1073-7. https://doi. org/10.1007/s11033-011-0833-z

24. Wood JD, Richardson RI, Nute GR, et al. Effects of fatty acids on meat quality: a review. Meat Sci 2004;66:21-32. https:// doi.org/10.1016/S0309-1740(03)00022-6

25.Schiavone A, Chiarini R, Marzoni M, Castillo A, Tassone S, Romboli I. Breast meat traits of Muscovy ducks fed on a microalga (Crypthecodinium cohnii) meal supplemented diet. Br Poult Sci 2007;48:573-9. https://doi.org/10.1080/ 00071660701615796

26. Geldenhuys G, Hoffman LC, Muller N. Aspects of the nutritional value of cooked Egyptian goose (Alopochen aegyptiacus) meat compared with other well-known fowl species. Poult Sci 2013;92:3050-9. https://doi.org/10.3382/ps.2013-03342

27. Alonso V, Campo MDM, Español S, Roncalés P, Beltrán JA.
Effect of crossbreeding and gender on meat quality and fatty acid composition in pork. Meat Sci 2009;81:209-17. https:// doi.org/10.1016/j.meatsci.2008.07.021

28. Aldai N, Murray BE, Oliván M, et al. The influence of breed and mh-genotype on carcass conformation, meat physicochemical characteristics, and the fatty acid profile of muscle from yearling bulls. Meat Sci 2006;72:486-95. https://doi.org/ 10.1016/j.meatsci.2005.08.016

29. Wood JD, Enser M, Fisher AV, et al. Fat deposition, fatty acid composition and meat quality: A review. Meat Sci 2008;78: 343-58. https://doi.org/10.1016/j.meatsci.2007.07.019

30.Nuernberg K, Fischer A, Nuernberg G, Ender K, Dannenberger $\mathrm{D}$. Meat quality and fatty acid composition of lipids in muscle and fatty tissue of Skudde lambs fed grass versus concentrate. Small Rumin Res 2008;74:279-83. https://doi. org/10.1016/j.smallrumres.2007.07.009

31. Teye GA, Sheard PR, Whittington FM, Nute GR, Stewart A, Wood JD. Influence of dietary oils and protein level on pork quality. 1. Effects on muscle fatty acid composition, carcass, meat and eating quality. Meat Sci 2006;73:157-65. https://doi. org/10.1016/j.meatsci.2005.11.010

32.Chen XD, Ma QG, Tang MY, Ji C. Development of breast muscle and meat quality in Arbor Acres broilers, Jingxing 100 crossbred chickens and Beijing fatty chickens. Meat Sci 2007;77:220-7. https://doi.org/10.1016/j.meatsci.2007.03.008

33. Berri C, Le Bihan-Duval E, Debut M, et al. Consequence of muscle hypertrophy on characteristics of Pectoralis major muscle and breast meat quality of broiler chickens. J Anim Sci 2007;85:2005-11. https://doi.org/10.2527/jas.2006-398 